\title{
Trivalent Antigens for Degranulation of Mast Cells
}

\author{
Richard G. Posner ${ }^{\dagger, \ddagger}$, Dianliang Geng ${ }^{\S}$, Seth Haymore ${ }^{\ddagger}$, James Bogert ${ }^{\ddagger}$, Israel Pecht ${ }^{\#}$, Arie \\ Licht $^{\#}$, and Paul B. Savage ${ }^{*}, \S$ \\ tDepartment of Computational Biology, Translational Genomics Research Institute, Phoenix, AZ \\ 85004 \\ ‡Department of Biology, Northern Arizona University, Flagstaff, AZ 86011 \\ §Department of Chemistry and Biochemistry, Brigham Young University, Provo, UT 84602 \\ \#Department of Immunology, Weizmann Institute of Science, Rehovet Israel
}

\begin{abstract}

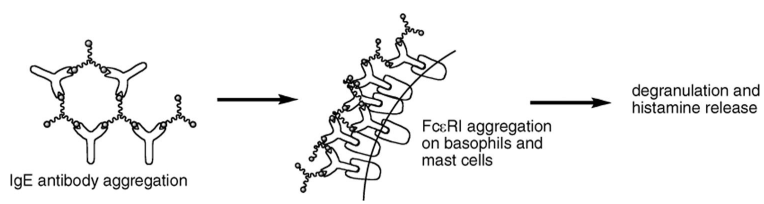

Degranulation of basophils and mast cells, releasing histamine, plays a central role in allergic reactions. Degranulation is a response to cell surface receptor aggregation caused by association of receptors with antibodies bound to multivalent antigens. Tools used in studying this process have included small-molecule divalent antigens, but they suffer from weak signaling due to small aggregate size. We have prepared trivalent antigens that allow formation of larger aggregates and potent responses from mast cells.
\end{abstract}

Aggregation of cell surface receptors is a common mechanism involved in signal transduction across cell membranes. ${ }^{1}$ This mechanism is used, for example, by receptors that are intrinsic protein tyrosine kinases (i. e., autophosphorylation of aggregated receptors), 2,3 such as the epidermal growth factor receptor, the platelet derived growth factor receptor, and the high affinity receptor for IgE (Fce RI), which plays a central role in allergic reactions. ${ }^{4,5}$ Early steps in the initiation of signaling by this class of receptors are similar: multivalent interactions with a ligand lead to aggregation of receptors and enhanced phosphorylation of tyrosines, which can be recognized by cytoplasmic regulatory molecules.

FceRI receptors are found on the surface of mast cells, basophils, and rat basophilic leukemia (RBL) cells, and these receptors bind the Fc (invariant) region of the divalent antibody IgE. When multiple IgE molecules bind a polyvalent antigen and in turn associate with FceRI on a cell surface, aggregates of these receptors are generated (Figure 1). Formation of aggregates can in some cases trigger calcium release and degranulation (export of histamine).

*paul_savage@byu.edu .

Supporting Information Available: Experimental details for the degranulation experiments; a synthetic scheme for 8a and 8b; synthetic details for the preparation of the di- and tri-valent antigens $(6 \mathbf{a}, 6 \mathbf{b}, 7 \mathbf{a}, 7 \mathbf{b}, 8 \mathbf{a}$ and $8 \mathbf{b})$; and ${ }^{1} \mathrm{H}$ NMR spectra for $6 \mathbf{a}, 6 \mathbf{b}, 7 \mathbf{a}$, $7 \mathbf{b}, \mathbf{8 a}$ and $8 \mathbf{b}$. 
Signals generated by Fc\&RI aggregation depend on various properties of the aggregate structures that are formed on the cell surface including the size of aggregates, ${ }^{6}$ the spacing of receptors in aggregates ${ }^{7}$, and the time that individual receptors spend within a complex. ${ }^{8}$

For example, it has been observed that aggregation caused by IgE dimers are less effective than those caused by larger IgE oligomers at stimulating cellular responses ${ }^{6}$ and that cellular responses are inhibited when an optimal degree of aggregation is exceeded. ${ }^{9}$ The factors that cause an aggregate to be a robust signaling unit, an inhibitor of signal transduction, or a nonsignaling unit remain to be fully elucidated.

The importance of influences of ligand-induced receptor aggregates on cellular signals has prompted significant effort in developing means for quantitative analysis of the interactions between multivalent ligands and cell surface receptors. ${ }^{10}$ An attractive approach to studing IgE - FceRI aggregation involves the use of synthetic symmetric divalent ligands, which are the simplest type of ligand capable of aggregating receptors. The interaction of divalent $\operatorname{IgE}$ antibodies with a divalent ligand can result in an IgE - FceRI aggregate spectrum that contains only linear chains and rings of various sizes (including one to one complexes) (Figure 1B). This limited spectrum of aggregates makes divalent ligands much easier to study theoretically than ligands of valences higher than two, which can form highly branched aggregates. A primary goal of studies performed with divalent ligands has been to measure or predict the number of receptors in aggregates on the cell surface, so that this quantity then can be compared and correlated with cellular responses. ${ }^{11}$ However, a major limitation of divalent ligands studied to date is their inability to activate strong cellular responses. Evidence suggests that these ligands are poor initiators of cell signaling because they aggregate receptors predominantly in the form of stable cyclic dimers. ${ }^{12}$ Modeling suggests that cyclic dimers, in which two ligand molecules connect two IgE - FceRI complexes to form a closed ring, prevent chain elongation, limit the size of ligand-induced aggregates, and may generate an inhibitory signal. ${ }^{13}$

In contrast to divalent antigens, trivalent antigens are predicted to form larger, highly branched aggregates (Figure 1B) leading to strong responses by IgE - Fc\&RI presenting cells (Figure 1C). Recently, Whitesides and coworkers ${ }^{14}$ reported the preparation of a trivalent antigen capable of aggregating IgE. They found that aggregates formed with stoichiometries of 3:2 (IgE:trivalent ligand). In this manuscript we describe the synthesis of a series of diand trivalent ligands and comparison of their relative ability to stimulate degranulation in IgE sensitized RBL cells. We find that the trivalent ligands are potent antigens causing degranulation at nanomolar concentrations, while analogous divalent antigens are inactive by comparison.

In allergic responses resulting in release of histamine, IgE targeting a nearly limitless variety of antigens may be involved. To simplify experiments, monoclonal IgE that associates with dinitrophenyl groups is used, and multivalent antigens therefore contain multiple dinitrophenyl amines. RBL cells are readily culturable and respond strongly to receptor aggregation and consequently are useful in measuring responses to polyvalent antigens. Measurement of degranulation is made by spectroscopic determination of the activity of granule-stored $\beta$-hexosaminidase secreted into the supernatant on $p$-nitrophenyl- $N$-acetyl- $\beta$ D-glucosamine.

Design considerations of the multivalent antigens included the length of the tether between dinitrophenylamine groups and an attachment point for an additional fluorophore. In earlier work, we determined that separation of antigens of more than $40 \AA$ was sufficient to allow efficient binding to IgE and subsequent aggregation of FceRI. ${ }^{15}$ 
To ensure that a tether of adequate length was generated, we prepared tethers derived from both tetra- and pentaethylene glycol. Based on modeling of the tethers (MMFF with Spartan) a maximum separation of 43.3 and $49.5 \AA$ A between dinitrophenylamine groups was predicted for the tetraethylene and pentaethylene glycol-based compounds, respectively. The tethers were prepared using Schwabacher's effective desymmetrization procedure of a diazide ${ }^{16}$ giving $\mathbf{1 a}$ and $\mathbf{1 b}$ (Scheme 1), followed by reaction with fluorodinitrobenzene and reduction providing $\mathbf{2} \mathbf{a}$ and $\mathbf{2} \mathbf{b}$.

Design of trivalent antigens was based on a trishydroxymethylaminomethane (Tris) core because this compound allows rapid generation of trivalent antigens. In addition, the amine group in Tris provides a reactive group for attachment of labels including fluorophores that can be included to allow fluorescent observation of binding events. The Tris core has been used by multiple groups for generation of dendrimers and other multivalent compounds, ${ }^{17,18}$ and the initial step in extending groups from Tris typically involves $1-4$ addition to acrylates. ${ }^{17} \mathrm{We}$ used $t$-butyl acrylate appended Tris ( $\mathbf{3}$ in Scheme 2). Reaction of the free amine in $3^{18}$ with activated Fmocglycine and unmasking of the three acid groups gave $\mathbf{4}$. Attachment of the tethered dinitrophenylamines through amide bonds was followed by removal of the Fmoc protecting group yielding $\mathbf{5 a}$ and $\mathbf{5 b}$. Reaction with succinimidyl esters of Alexa-488 or fluorescein gave the series of labeled trivalent antigens $6 \mathbf{a}$ and $\mathbf{6 b}$ and $7 \mathbf{a}$ and $7 \mathbf{b}$.

To compare the differences between divalent antigens capable of generating only linear and cyclic aggregates and trivalent antigens capable of generating highly branched aggregates, divalent antigens $8 \mathbf{a}$ and $\mathbf{8 b}$ (Figure 2) were prepared using $\mathbf{2 a}$ and $\mathbf{2 b}$ and serinol as a core. The methodology described in Scheme 2 was used for preparation of these compounds (see Supporting Information).

The abilities of each of the tri- and di-valent antigens to stimulate degranulation were measured using the enzymatic assay described above. The results are shown in Figure 3. All assays were repeated at least four times and their results are expressed as net percent of the cells' total enzyme activity contents $\pm 5-10 \%$.

Trivalent antigens $6 \mathbf{a}, \mathbf{6 b}, 7 \mathbf{a}$ and $7 \mathbf{b}$ all proved to be very potent stimulators of RBL cells, with degranulation occurring in response to concentrations of the antigens below the $\mathrm{n} M$ level. The differences in stimulation between the trivalent antigens with Alexa-488 and those with fluorescein may be attributable to the higher solubility of Alexa-488, which may decrease self aggregation. The tether lengths exerted a modest influence on the level of degranulation with longer tether lengths $(\mathbf{6 b}$ and $\mathbf{7 b})$ providing greater degranulation than the antigens with shorter tether lengths.

It is significant that above a threshold concentration of the trivalent antigens, degranulation drops off. Cross-linking increases with ligand concentration up to an optimal ligand concentration and then decreases as monovalent binding, because of excess ligand, begins to predominate. For any polyvalent ligand interacting with a bivalent recepor (such as IgE), one expects that the cross-linking curve, i.e., a plot of the degree of aggregation vs. the concentration of ligand, is bell shaped.

Results with $8 \mathbf{a}$ and $\mathbf{8 b}$ are notable because over the concentration range shown no degranulation above background was observed. Because the divalent ligand and trivalent antigens are expected to have similar binding affinities between their dinitrophenylamine groups and the IgE binding sites and the spacing between dinitrophenylamines are the same, it seems likely that the differences in cellular response occur because aggregates formed by the trivalent antigens are not simple "cyclic dimers" but rather more complex networks and branched structures (Figure 1). Considering this concentration range and the concentration at 
which the trivalent antigens begin to provide signaling for degranulation, it is apparent that the trivalent antigens are at least 1,000 times better at generating aggregates that provide a positive signal.

In conclusion, degranulation in response to the trivalent antigens is notable because these symmetric trivalent antigens are the first (and simplest) well-defined, synthetic ligands produced to date that generate the same type of strong cellular signals that one observes with highly polyvalent antigens such as conjugated proteins (polydinitrophenyl-bovine serum albumin, ${ }^{13}$ polydinitrophenyl-polyethylene glycol ${ }^{19}$ ) in this cell system. It is anticipated that these small, potent, fluorophore-labeled antigens will facilitate study of receptor aggregation on cell surfaces and signaling that leads to allergic responses.

\section{Supplementary Material}

Refer to Web version on PubMed Central for supplementary material.

\section{Acknowledgments}

Funding from the National Institutes of Health (NIAID AI35997) is gratefully acknowledged.

\section{References}

1. Metzger H. J. Immunol. 1992; 149:1477. [PubMed: 1324276]

2. Pazin MJ, Williams LT. Trends Biochem. Sci. 1992; 17:374. [PubMed: 1455504]

3. Fry MJ, Panayotou G, Booker GW, Waterfield MD. Protein Sci. 1993; 2:1785. [PubMed: 8268793]

4. Keegan AD, Paul WE. Immunol. Today. 1992; 13:63. [PubMed: 1575894]

5. Holowka D, Baird B. Annu. Rev. Biophys. Biomol. Struct. 1996; 25:79. [PubMed: 8800465]

6. Fewtrell C, Metzger H. J. Immunol. 1980; 125:701. [PubMed: 7391576]

7. Kane P, Ericksion J; Fewtrell, C. Baird B, Holowka D. Mol. Immunol. 1986; 23:783. [PubMed: 2948111]

8. Torigoe C, Inman JK, Metzer H. Science. 1998; 281:568. [PubMed: 9677201]

9. Seagrave J, Oliver JM. J. Cell Physiol. 1990; 144:128. [PubMed: 2142164]

10. Hlavacek WS, Perelson AS, Sulzer B, Bold J, Paar J, Gorman W, Posner RG. Biophys. J. 1999; 76:2421. [PubMed: 10233059]

11. Posner RG, Subramanian K, Feder T, Thomas J, Holowka D, Baird B, Goldstein B. J. Immunol. 1995; 155:3601. [PubMed: 7561059]

12. Schweitzer-Stenner R, Licht A, Pecht I. Biophys. J. 1992; 63:563. [PubMed: 1420898]

13. Harris NT, Goldstein B, Holowka D, Baird B. Biochemistry. 1997; 36:2237. [PubMed: 9047325]

14. Bilgicer B, Moustakas D, Whitesides GM. J. Am. Chem. Soc. 2007; 129:3722. [PubMed: 17326636]

15. Posner RG, Savage PB, Peters AS, Macias A, DelGado J, Schwarz G, Sklar LA, Hlavacek W, Goldstein B. Molecular Immunology. 2002; 38:1221. [PubMed: 12217387]

16. Schwabacher AW, Lane JW, Schiesher MW, Leigh KM, Johnson CW. J. Org. Chem. 1998; 63:1727.

17. (a) Rensen PCN, van Leeuwen SH, Sliedregt LAJM, Van Berkel TJC, Biessen EA. J. Med. Chem. 2004; 47:5798. [PubMed: 15509179] (b) Kawa M, Takahagi T. J. Polymer Sci. B: Polymer Physics. 2004; 42:2680.For examples see:

18. Claudia MC, Robert EG. J. Org. Chem. 2002; 67:1411. [PubMed: 11846699]

19. Baird EJ, Holowka D, Coates GW, Baird B. Biochemistry. 2003; 42:12739. [PubMed: 14596588]

Org Lett. Author manuscript; available in PMC 2012 March 15. 
A<smiles></smiles>

divalent antigen

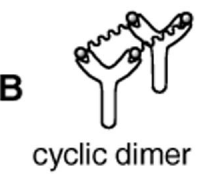

aggregates with a divalent antigen

C

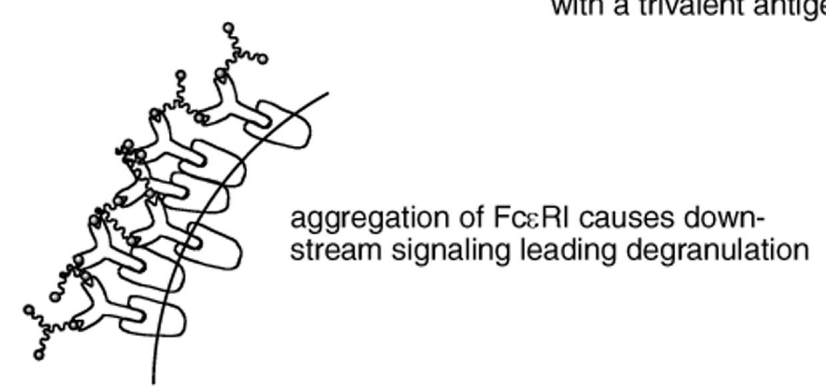

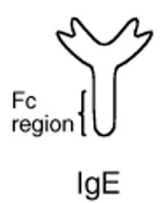
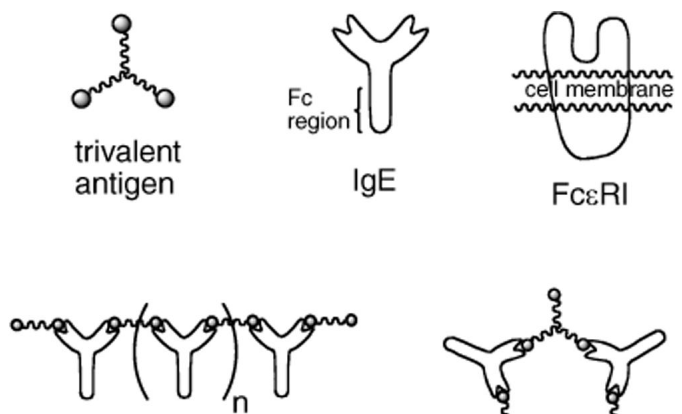

linear polymer

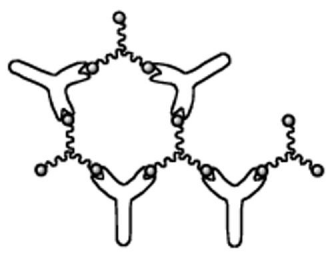

highly branched aggregate with a trivalent antigen

Figure 1.

A: Schematic representation of ligands, antibodies and receptors involved in degranulation. B: IgE aggregates formed with di- and trivalent antigens. C: Aggregation of FceRI leading to aggregation. 


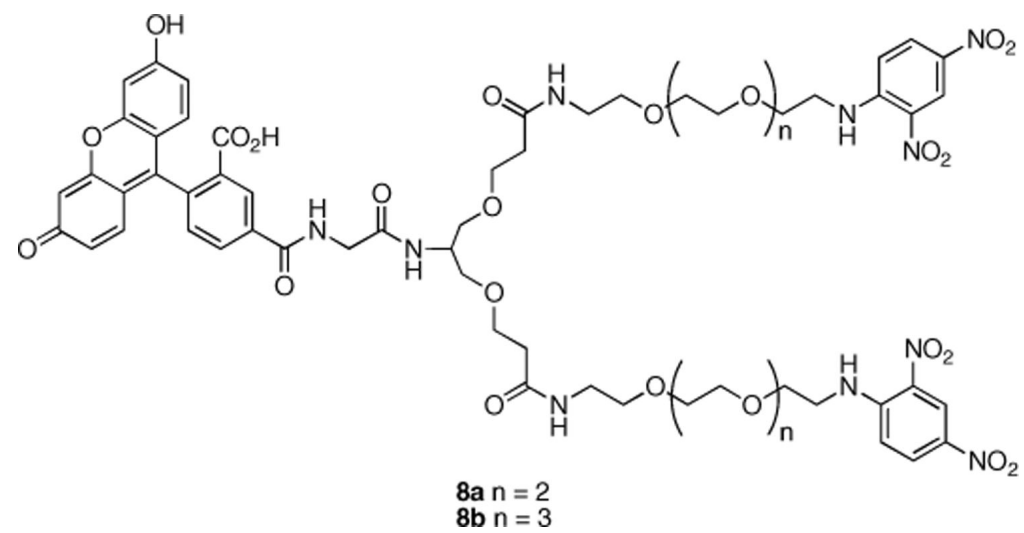

Figure 2.

Structures of divalent antigens $\mathbf{8 a}$ and $\mathbf{8 b}$. 


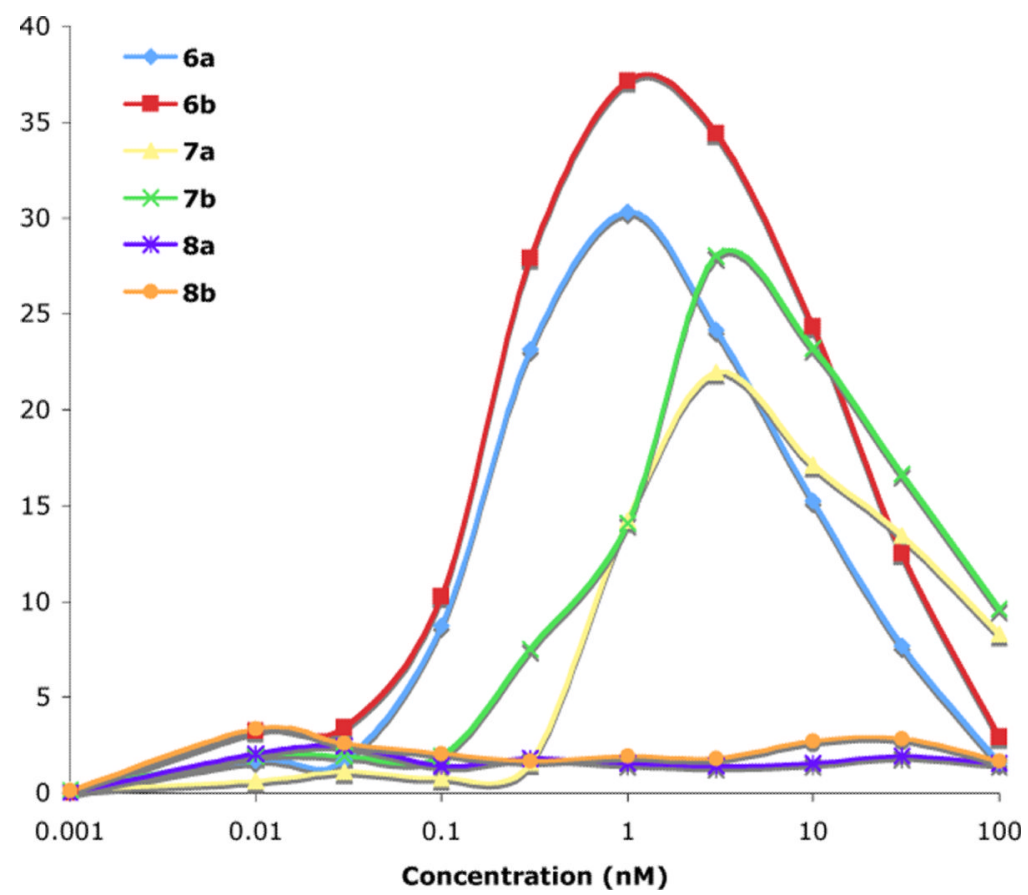

Figure 3.

Degranulation by mast cells (RBL-2H3 cells) in response to di- and tri-valent antigens as measured by $\beta$-hexosaminidase activity. 


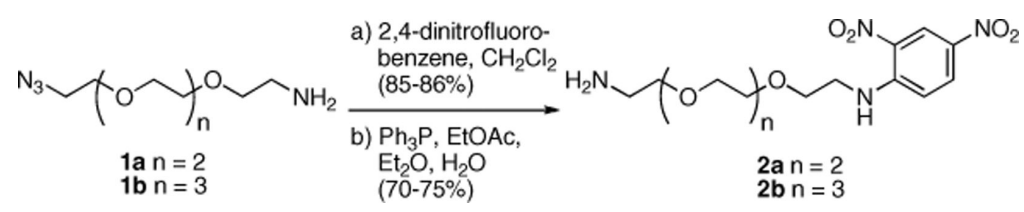

Scheme 1.

Preparation of dinitrophenyl-appended glycol linkers. 

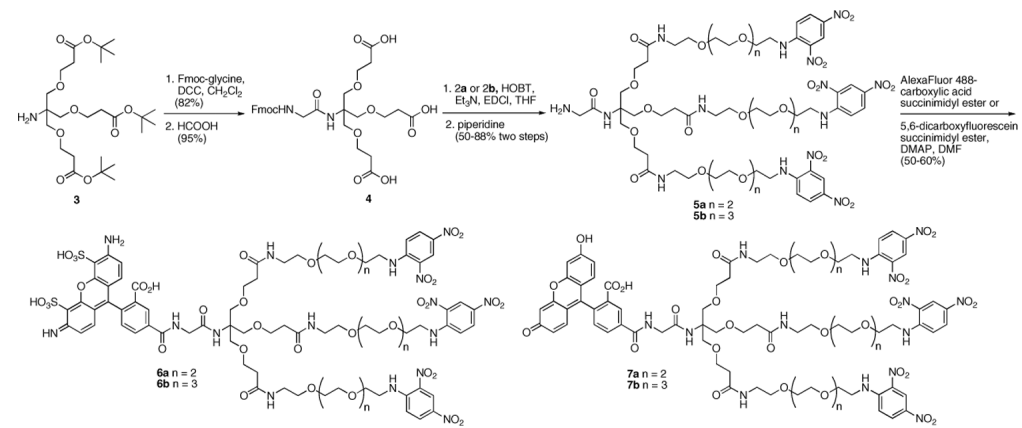

Scheme 2.

Preparation of fluorophore-appended trivalent antigens. 